\title{
Binding and Retrograde Transport of Leukemia Inhibitory Factor by the Sensory Nervous System
}

\author{
I. A. Hendry, ${ }^{1}$ M. Murphy, ${ }^{2,3}$ D. J. Hilton, ${ }^{2}$ N. A. Nicola, ${ }^{2,3}$ and P. F. Bartlett ${ }^{2,3}$ \\ 'The John Curtin School Of Medical Research, Australian National University, Canberra A.C.T. 2601, Australia, \\ ${ }^{2}$ The Walter and Eliza Hall Institute of Medical Research, Royal Melbourne Hospital, Parkville, Victoria 3050, Australia, and \\ ${ }^{3}$ The Cooperative Research Centre for Cellular Growth Factors, P.O. Royal Melbourne Hospital, Parkville, Victoria 3050, \\ Australia
}

Leukemia inhibitory factor (LIF), a peptide growth factor with multiple activities, has recently been shown to support the generation and survival of sensory neurons in cultures of mouse neural crest and dorsal root ganglia (DRG). We have conducted binding experiments with ${ }^{125} \mid$-LIF on cultures of DRG to determine the receptor distribution for LIF on these cells and found that at least $60 \%$ of the sensory neurons in the cultures bound ${ }^{125}$ I-LIF, all of which could be eliminated by the addition of unlabeled LIF. The other cells in the culture, which morphologically appeared to be Schwann cells, did not bind appreciable quantities of ${ }^{125}$-LIF. In order to investigate whether LIF is retrogradely transported to sensory neurons in vivo, ${ }^{125}$ I-LIF was injected into the footpads and gastrocnemius muscles of newborn and adult mice, following sciatic nerve ligation. Radioactivity accumulated in the distal portion of the sciatic nerve, indicating retrograde transport of LIF. Subsequent experiments on mice with unligated sciatic nerves showed that ${ }^{125} \mathrm{I}$-LIF is specifically transported into the sensory neurons of the DRG. There was no apparent transport of ${ }^{125}$-LIF into motor neurons in the spinal cord. These experiments demonstrate that LIF can specifically bind to and be transported by sensory neurons and further support the idea that LIF acts as a target-derived neurotrophic factor, analogous to NGF.

During normal development, at the time of target innervation, a large proportion of the initially produced neurons die (Hamburger, 1975, 1977; Purves et al., 1988). Removal of the target tissue prior to innervation results in a massive increase in the extent of cell death (Hamburger, 1934; Cowan, 1970), suggesting that the target tissue is able to provide neurotrophic support that promotes the survival of the innervating neurons (Hendry, 1976). NGF was the first, and remains the best, example of a factor that provides this neurotrophic support (Levi-Montalcini and Angeletti, 1968; Purves et al., 1988; Oppenheim, 1989). Since then, other putative neurotrophic factors have been identified, including the neurotropins (NTs), brain-derived neurotrophic factor and NT-3, which share structural homology to

\footnotetext{
Received Aug. 21, 1991; revised Jan. 21, 1992; accepted Mar. 27, 1992.

We thank Mrs. M. Preston and Kate Reid for skillful technical assistance and S. Mihajlovic for histology. This work was supported by the National Health and Medical Research Council of Australia, Sandoz Corporation, Switzerland, Amrad Corporation, Melbourne, Australia, and the Australian Government Research Centres Scheme.

Correspondence should be addressed to Dr. Perry F. Bartlett, The Walter and Eliza Hall Institute of Medical Research, Post Office, Royal Melbourne Hospital, Parkville, Victoria 3050, Australia.
}

Copyright (C) 1992 Society for Neuroscience $0270-6474 / 92 / 123427-08 \$ 05.00 / 0$
NGF (Leibrock et al., 1989; Hohn et al., 1990) and ciliary neurotrophic factor (CNTF; Barbin et al., 1984; Stöckli et al., 1989).

In addition to their classical action of supporting neuron survival at the critical phase, some factors have been recently shown to play a role in the earlier stages of neural development. Fibroblast growth factor (FGF) and insulin-like growth factors (IGF), especially IGF-1, appear to be involved in the regulation of proliferation and differentiation of neural precursor cells (Murphy et al., 1990; Drago et al., 1991). As both these factors have been shown to be endogenously produced by neuroepithelial cells (Drago et al., 1991), it has been proposed that some factors may regulate neural development through an autocrine or paracrine mechanism (Bartlett and Murphy, 1991, 1992).

I Iowever, except for NGF, none of the factors so far described have been unequivocally shown to play a role in neural development in vivo. Among the criteria to be fulfilled for a factor to be ascribed neurotrophic function is that it bind directly to receptors on the putative target neuron. Another appears to be the requirement for the factor, taken up by nerve terminals, to be retrogradely transported to the neuronal perikarya (Hendry 1976; Thoenen and Edgar, 1985; Oppenheim, 1989). To date, only NGF fulfills both of these criteria. In this report, we demonstrate that leukemia inhibitory factor (LIF), a factor that has been shown to induce the switching of neurotransmitter phenotype in sympathetic neurons (Yamamori et al., 1989) and to act as both a differentiating and survival factor in the sensory neuron lineage (Murphy et al., 1991), binds to the majority of sensory neurons in vitro and is retrogradely transported by sensory neurons in vivo in the dorsal root ganglion (DRG). These findings further support its role as a physiologically important neurotrophic factor in the developing sensory nervous system.

\section{Materials and Methods}

Purification and radioiodination of LIF and FGF. Recombinant LIF was produced in Escherichia coli as a nonglycosylated protein. The purified species electrophoresed with an apparent molecular weight of 20,000 and an isoelectric point of yreater than 9.0 (Gearing et al., 1987; D. J. Hilton, unpublished observation). Iodination of LIF was performed by the iodine monochloride method (Contreras et al., 1983) as described previously (Hilton et al., 1991). Briefly, $6 \mu \mathrm{l}$ of a $1 \mathrm{mg} / \mathrm{ml}$ solution of LIF in $40 \%(\mathrm{v} / \mathrm{v})$ acetonitrile, $0.1 \%(\mathrm{v} / \mathrm{v})$ trifluoroacetic acid, and $0.02 \%(\mathrm{v} / \mathrm{v})$ Tween 20 was iodinated by addition of $1 \mathrm{mCi} \mathrm{Na}^{125} \mathrm{I}$ (New England Nuclear, North Ryde, New South Wales, Australia), 40 $\mu \mathrm{l}$ of $200 \mathrm{~mm}$ sodium phosphate, $0.02 \%(\mathrm{v} / \mathrm{v})$ Tween 20 at $\mathrm{pH} 7.4$ (PBS), and, while vortex mixing, $3 \mu \mathrm{l}$ and then $6 \mu \mathrm{l}$ of $200 \mu \mathrm{M} \mathrm{ICI}$ in $2 \mathrm{M} \mathrm{NaCl}$. After $1 \mathrm{~min}$ at room temperature, radioiodinated LIF ( ${ }^{125}$ I-LIF) was separated from unincorporated ${ }^{125} \mathrm{I}$ by sequential gel filtration and cation-exchange chromatography. ${ }^{25}$ I-LIF produced in this manner rctained full biological activity and was more than $99 \%$ precipitable with cold $20 \%(\mathrm{w} / \mathrm{v})$ trichloroacetic acid, and greater than $90 \%$ of the radio- 
activity was capable of binding specitically to Ml cells (Hilton et al. 1988). The specific radioactivity was $1100 \mathrm{cpm} / \mathrm{fmol}(500 \mathrm{Ci} / \mathrm{mmol})$, as determined by self-displacement analyses (Calvo et al., 1983). ${ }^{125}$ Ilabeled acidic FGF (specific activity, $800 \mathrm{Ci} / \mathrm{mmol}$ ) was obtained as a gift from Amersham (Buckinghampshire, UK).

Binding experiments and autoradiography. Single cell suspensions were prepared from dorsal root ganglion cells from postnatal day 2 mice as previously described (Murphy et al., 1991) and were plated at $10^{4}$ cells per well into eight-chamber culture slides (Nunc Inc., Naperville, IL) in Monomed medium (CSL, Melbourne, Australia) containing $10 \%$ $(\mathrm{v} / \mathrm{v})$ fetal calf serum (FCS), but no added growth factors, and cultured overnight in a humidified incubator at $37^{\circ} \mathrm{C}$. The slides were then incubated on ice for $2 \mathrm{hr}$ in $20 \mathrm{ml}$ of HEPES-buffered RPMI-1640 medium, containing $10 \%(\mathrm{v} / \mathrm{v}) \mathrm{FCS}$, with or without $10 \mu \mathrm{g} / \mathrm{ml}$ of unlabeled $\mathrm{LIF}$, and $5 \times 10^{4} \mathrm{cpm}$ of ${ }^{125} \mathrm{I}$-LIF. The slides were washed three times in $300 \mathrm{ml}$ of PBS, fixed in 10\% formalin in PBS for $2 \mathrm{hr}$, and then rinsed in water. Slides were dipped in NTB-2 photographic emulsion (Kodak) at $42^{\circ} \mathrm{C}$ in a darkroom and allowed to dry. Slides were then sealed in a lightproof box containing Drierite and exposed for $2-8$ weeks at $4{ }^{\circ} \mathrm{C}$, and then developed in Kodak D19, and fixed in Agfa G333C for $3 \mathrm{~min}$. Autoradiographs were examined at $400 \times$ and $1000 \times$ magnification, and where necessary, grain counts were performed on at least 250 cells for each condition and background counts were subtracted.

Immunohistochemistry. Slides of dorsal root ganglion cells that had been fixed in formalin were immunostained with a rabbit anti-150 kDa neurofilament antibody (Chemicon, Temecula, CA) and a rhodamineconjugated sheep anti-mouse antibody prior to them being dipped in NTB-2 emulsion, as previously described (Murphy et al., 1991).

Retrograde transport and labeling of neurons with ${ }^{125} I-L I F$. The sciatic nerves of newborn and adult $\mathrm{Balb} / \mathrm{C}$ mice were ligated on both sides in the region of the midthigh using 6-0 prolene monofilament (Ethicon, Sydney, Australia). The radioactive proteins were then injected unilaterally either intradermally into the foot or intramuscularly into the center of the gastrocnemius muscle. After various intervals, the animals were killed by ether overdose and both sciatic nerves dissected. To follow transport of ${ }^{125}$ I-LIF in the sciatic nerve, the nerves were cut at the ligation point, $2 \mathrm{~mm}$ pieces were taken immediately proximal and distal to the ligation point, and radioactivity was determined directly.

To measure accumulation of ${ }^{125}$ I-LIF or ${ }^{125}$ I-FGF in the dorsal root ganglia (DRG), newborn and adult mice were injected in the footpad and $16 \mathrm{hr}$ later their ganglia from T13 to S1 were removed with the aid of a dissecting microscope, and the radioactivity was estimated in the whole ganglion in a gamma counter. Each sample was counted for 10 min and background subtracted. Similarly, the particular sympathetic ganglia were removed following injection of ${ }^{125}$ I-LIF into the feet or eye and processed as above. For cold competition experiments, a 900 -fold excess of unlabeled LIF $\left(20 \mu \mathrm{g} ; 0.5 \mu \mathrm{Ci}\right.$ of $\left.{ }^{125} \mathrm{I}-\mathrm{LIF}=22 \mathrm{ng}\right)$ was coinjected with the ${ }^{125} \mathrm{I}-\mathrm{LIF}$ and $16 \mathrm{hr}$ later the ganglia were processed as above. Selected ganglia or spinal cords with attatched ganglia were dissected from the animals and fixed in $4 \%$ paraformaldehyde in PBS prior to being embedded in paraffin. Serial sections $(7 \mu \mathrm{m})$ were cut, mounted, dewaxed, and dipped in NTB-2 emulsion. The sections were developed 3-4 weeks later and stained with hemotoxylin and eosin, and ganglia and spinal cord were examined for labeled cells.

\section{Results}

LIF binds specifically to DRG neurons in vitro

Previous studies have shown that LIF supported the survival in vitro of the majority of sensory neurons obtained from the DRG of newborn mice (Murphy et al., 1991). LIF was effective even at very low cell numbers and single neurons could be supported, indicating that the action of LIF on sensory neurons is most probably direct and not via accessory cells. To establish that sensory neurons express LIF receptors, binding studies were carried out on cells isolated from sensory ganglia. The cells were cultured overnight to allow the cells to adhere and acquire morphological features characteristic of the cell types in the ganglia, which are mainly sensory neurons and Schwann cells. The cultures were then incubated with ${ }^{125}$ I-LIF and subjected to autoradiography. As shown in Figure 1, many of the neurons (large round cells, staining positively for neurofilament; data not shown) in these cultures bound ${ }^{125} \mathrm{I}-\mathrm{LIF}$. The grains appeared over the neuronal cell bodies or formed a halo around them as expected given the long pathway of ${ }^{125} \mathrm{I}$. In addition, there appeared to be a higher density of grains in the region over some neuronal processes, although it was impossible to localize the grains precisely over these processes because of the limited resolution of the procedure.

The great majority of other cells in the culture, most of which had the morphological appearance of Schwann cells, only displayed background numbers of grains, indicating that they did not bind LIF (Fig. 1). Counts of the number of grains over the cells showed that at least $60 \%$ of the neurons in these cultures bound significant amounts of ${ }^{125} \mathrm{I}-\mathrm{LIF}$, which was reduced to background levels by the addition of cold LIF (Fig. 2). Only 4\% of the non-neuronal cells in the culture bound significant levels of ${ }^{125}$ I-LIF.

\section{LIF is retrogradely transported in the sciatic nerve}

Having demonstrated the presence of LIF receptors on sensory neurons in vitro, it was next investigated whether the sciatic nerve could transport ${ }^{125} \mathrm{I}-\mathrm{I}$.IF in vivo, which would suggest that LIF is retrogradely transported by the sensory neurons in an analogous fashion to NGF (Hendry, 1976). The procedures used were essentially the same as those used originally to demonstrate the retrograde transport of NGF into sensory neurons. ${ }^{125}$ I-FGF was also used in these experiments, as others have found no retrograde transport of this factor in the sciatic nerve (Ferguson et al., 1990), albeit it appears to have trophic activity for sensory neurons in vivo (Otto et al., 1987). The iodinated ligands were injected into the gastrocnemius muscles and the footpads of adult mice whose sciatic nerves had been ligated. At different times, segments of sciatic nerve were taken from the proximal and distal sides of the ligation and radioactivity was determined. It was found that there was significant accumulation of radioactivity in the distal segment of the nerve after injection of ${ }^{125} \mathrm{I}-$ LIF, whether the ligand had been injected into the footpad or muscle (see Table 1). The time of this accumulation suggested that it was due to retrograde transport and not passively accumulated. There was no evidence for the distal accumulation of

\footnotetext{
Figure 1. Binding of LIF to DRG cells in vitro. Cultures of postnatal day 2 DRG were incubated with ${ }^{225}$ I-LIF and subjected to autoradiography as described in Materials and Methods. Shown are photomicrographs of the cultures using phase-contrast $(A, C, E, F)$ or dark-field $(B, D)$ illumination. Many of the neurons shown in $A$ contain numerous grains as revealed in the dark-field illumination in $B$ (thick arrows show an example); however, some of the neurons have few if any grains over them (thin arrows, e.g.). Binding studies conducted in the presence of an excess of cold LIF eliminates binding of ${ }^{125}$ I-LIF to the neurons $(C, D) . E$ and $F$ show high-power views of the same field at different focal planes, wherc $E$ is in the plane of the cells and $F$ is in the plane of the emulsion. Three neurons (round and highly refractile cell bodies) are present in the field: the upper neuron ( 1 ) has only background numbers of grains over its cell body; the central neuron (2) has many grains around the cell bbody and in the region over the processes (arrowed); the right neuron (3) has a low number of grains over the cell body but a high density in the region over the neuronal processes (arrowed). The other non-neuronal cells in the field, probably Schwann cells, show only background levels of grains over them. Scale bar: $A-D, 400 \mu \mathrm{m} ; E$ and $F, 80 \mu \mathrm{m}$.
} 

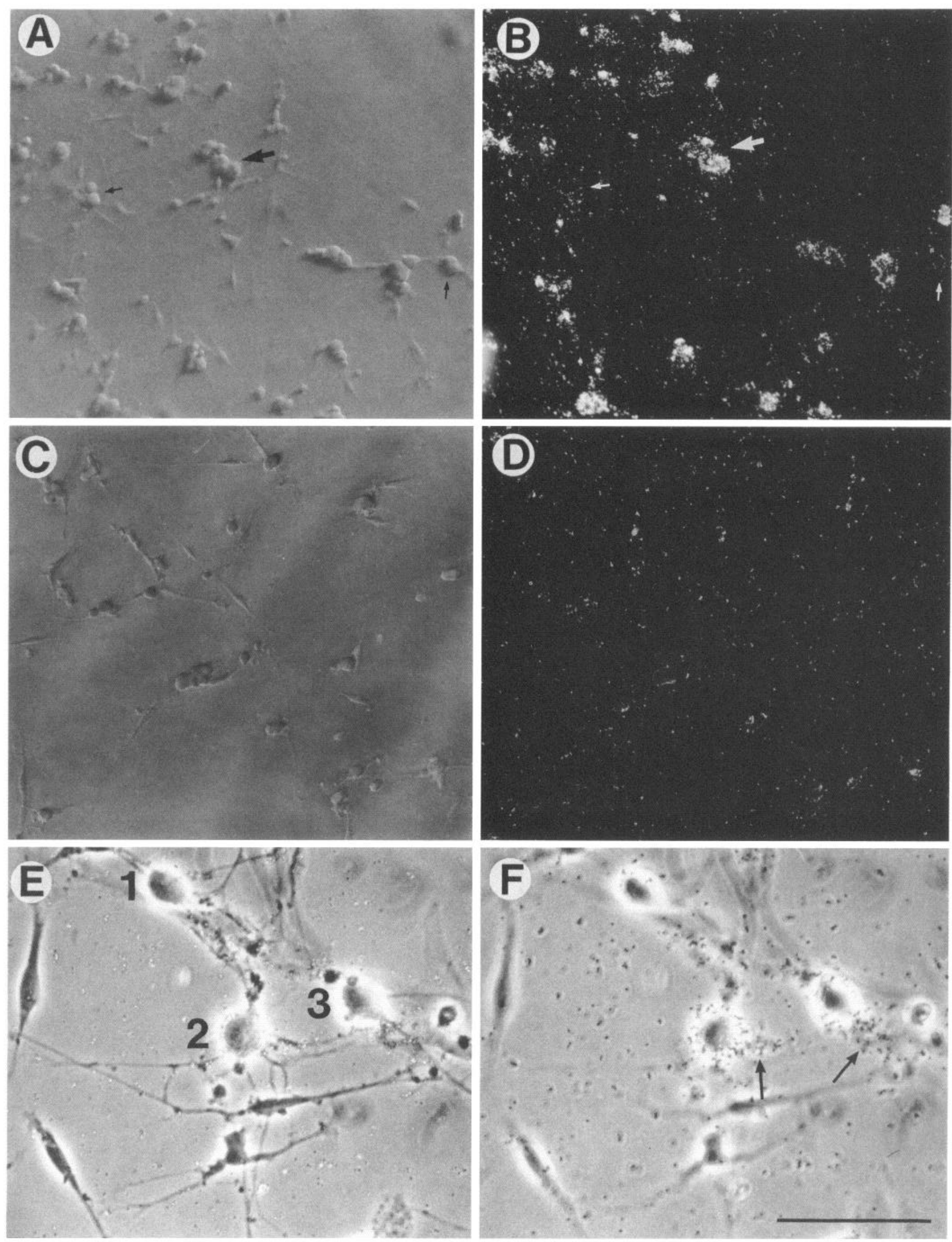

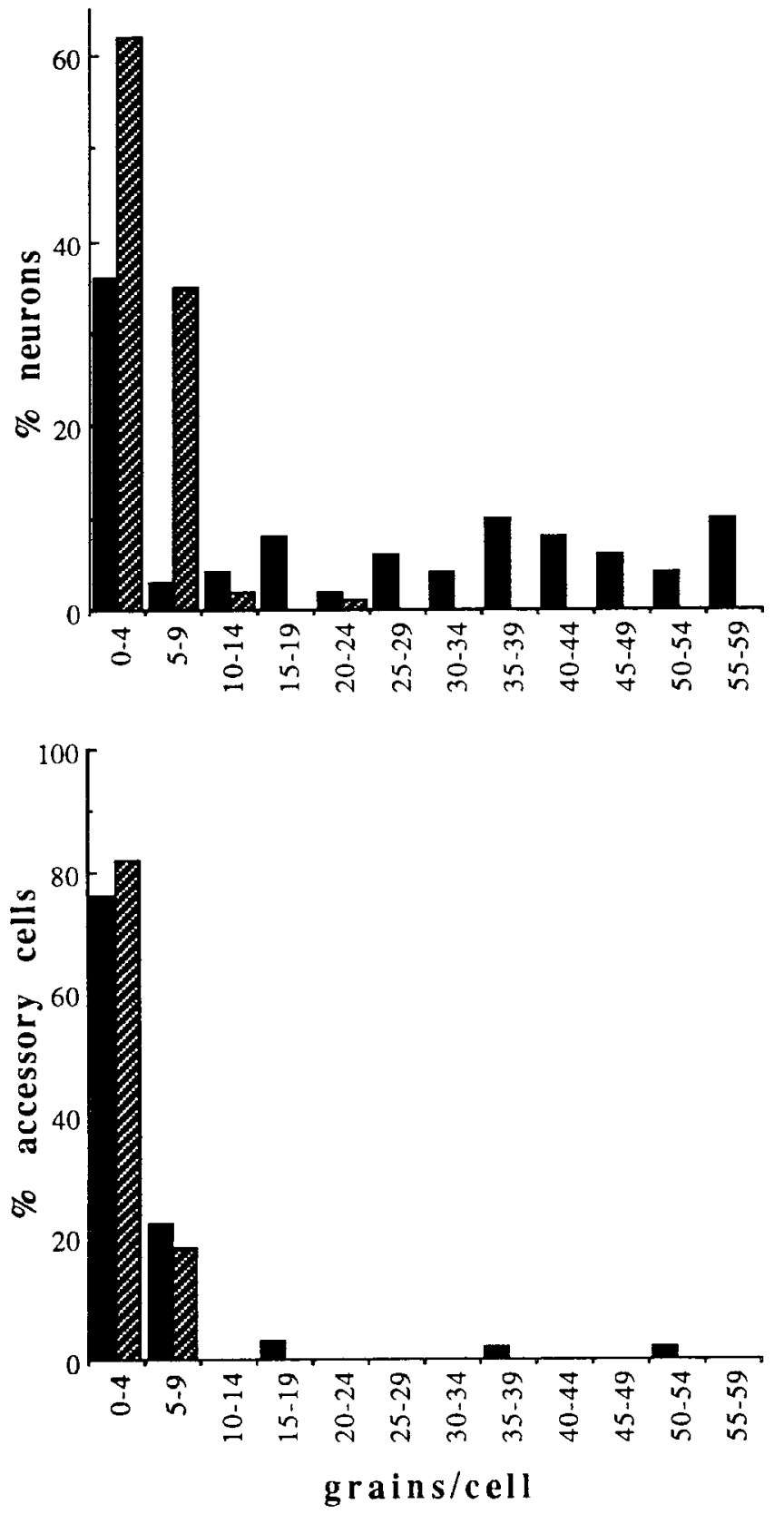

Figure 2. Distribution of autoradiographic grain counts in DRG cultures incubated with ${ }^{125}$ I-LIF. Numbers are expressed as percentage of neurons or non-neuronal cells in cultures incubated either with ${ }^{125}$ I-LIF alone (solid bars) or with the addition of an excess of unlabeled LIF (hatched bars).
${ }^{125} \mathrm{I}-\mathrm{FGF}$ (data not shown), which is in agreement with the previous studies of Ferguson et al. (1990).

\section{LIF is transported into sensory neurons in the DRG}

In order to examine more closely which neurons were involved in the retrograde transport of LIF, adult mice were again injected subcutaneously in the foot, or into muscle, but this time with the sciatic nerve intact. Sixteen hours later, the animals were killed, DRG and spinal cords removed, and radioactivity determined. In those animals injected in the skin of the foot, there was a significant accumulation of radioactivity in the sensory ganglia centered around lumbar ganglion 4 (L4; Fig. $3 A$ ). There was also accumulation of radioactivity in those animals injected in the gastrocnemius muscle, but this was considerably smaller than that from the footpad (Fig. 3A).

In order to determine whether the uptake and accumulation of ${ }^{125}$ I-LIF was saturable, a 900 -fold excess of unlabeled LIF $(20 \mu \mathrm{g})$ was co-injected with the ${ }^{125} \mathrm{I}-\mathrm{LIF}$ in the footpad of adult mice, the sensory ganglia removed $16 \mathrm{hr}$ later, and radioactivity determined. Figure $3 B$ shows that under these conditions, there was no accumulation of radioactivity over background levels, indicating that the unlabeled LIF blocked the transport of ${ }^{125} \mathrm{I}-$ LIF into the DRG. This further indicates that the uptake and transport of LIF into the DRG is probably receptor mediated.

A similar amount of ${ }^{125}$ I-FGF was also injected into the muscle and footpad of adult mice. As shown in Figure $3 \mathrm{C}$, there was no accumulation of ${ }^{125}$ I-FGF into the DRG $16 \mathrm{hr}$ after injection, which is consistent with the lack of accumulation of ${ }^{125} \mathrm{I}-\mathrm{FGF}$ in distal segments of the sciatic nerve and is in agreement with the findings of Ferguson et al. (1990).

Newborn mice were similarly injected, and in this case a significant accumulation of radioactivity occurred following injections into both the foot and leg (Fig. 4). The accumulation of radioactivity after skin injection again was centered on L4, whereas that from the muscle injection was more widespread but still maximal at L4 (Fig. 4). The accumulation of radioactivity in the more rostral ganglia may have been due to greater spread of radioactivity at the site of injection in the smaller animals. If this were the case, then the ${ }^{125}$ I-LIF could have been taken up by sensory axons farther up the leg and transported back to neuronal cell bodies farther up the spinal cord. The observation that the contralateral ganglia accumulated some radioactivity may be due to systemic spread of the ligand followed by specific binding and uptake into the DRG.

The accumulation of significant levels of radioactivity within $16 \mathrm{hr}$ in the DRG in both adult and neonatal animals is consistent with retrograde transport of ${ }^{125}$ I-LIF in the sensory axons.

Table 1. Injection of LIF into adult mice with ligated sciatic nerve

Accumulation of ${ }^{125}$ I-LIF into nerve

(fmol/2 mm) after injection into:

\begin{tabular}{llllll}
\multirow{2}{*}{$\begin{array}{c}\text { Time after } \\
\text { injection }(\mathrm{hr})\end{array}$} & Footpad & & \multicolumn{2}{l}{ Gastrocnemius muscle } \\
\cline { 2 - 3 } \cline { 5 - 6 } & Proximal $^{a}$ & Distal & & Proximal & Distal \\
\hline 7 & $0.14 \pm 0.2$ & $0.35 \pm 0.08$ & & $0.11 \pm 0.01$ & $0.49 \pm 0.13$ \\
16 & $0.17 \pm 0.03$ & $0.78 \pm 0.11$ & & $0.14 \pm 0.01$ & $0.55 \pm 0.13$ \\
24 & $0.06 \pm 0.01$ & $0.55 \pm 0.04$ & & $0.07 \pm 0.00$ & $0.40 \pm 0.14$ \\
\hline
\end{tabular}

The sciatic nerves were ligated in the midthigh region of adult mice and $1 \mu \mathrm{Ci}$ of ${ }^{125} \mathrm{I}-\mathrm{LIF}$ was injected into either one of the footpads or calves. After the various times, the nerve was removed, $2 \mathrm{~mm}$ sections either side of the ligature were taken, and radioactivity was measured in a gamma counter. Numbers are the means and SD of six determinations.

a Proximal and distal refer to where nerve stump was measured. 

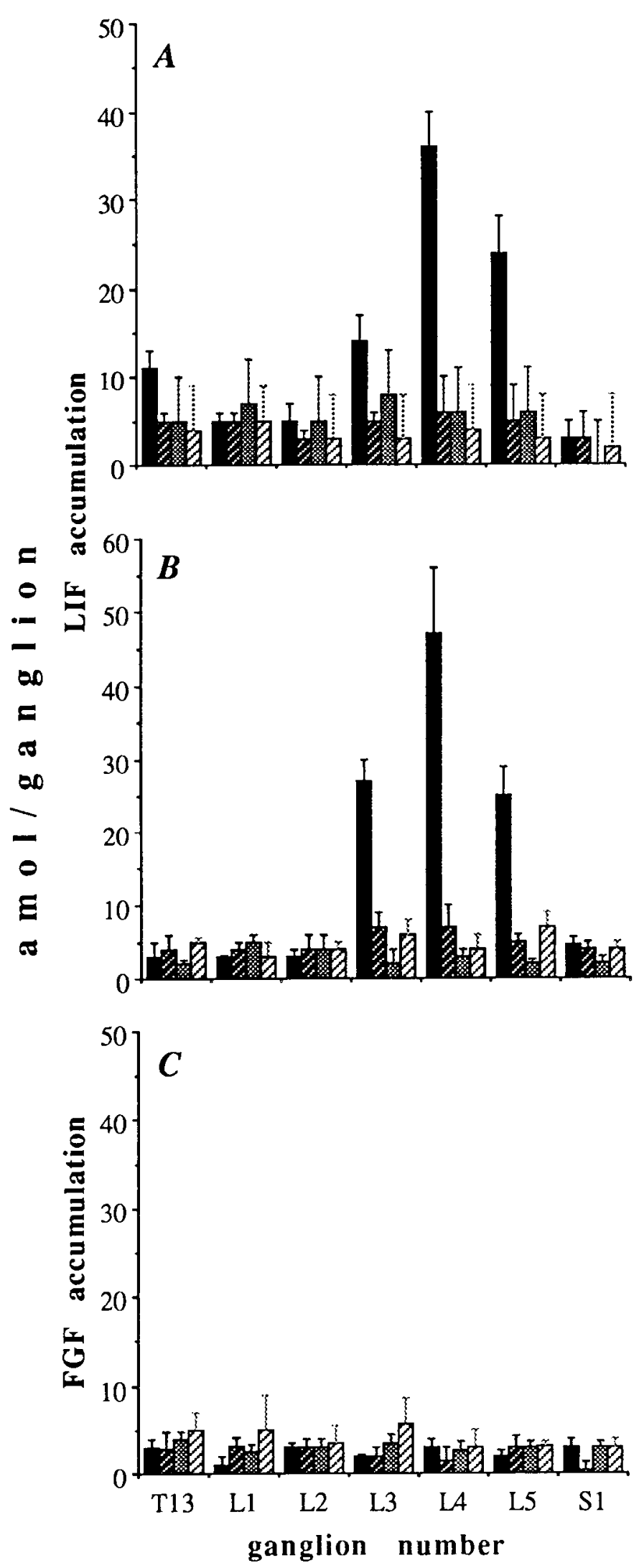

Figure 3. Retrograde axonal transport into sensory ganglia in adult mice. $A,{ }^{125} \mathrm{I}$-LIF was injected into the footpad or gastrocnemius muscle of adult mice, and $16 \mathrm{hr}$ later the mice were killed, DRG from thoracic $(T) 13$ and lumbar $(L)$ through to sacral $(S) 1$ were removed, and radioactivity was determined. Shown are accumulation (amoles of ${ }^{125}$ ILIF) in ganglia ipsilateral (black) or contralateral (heavily hatched) after

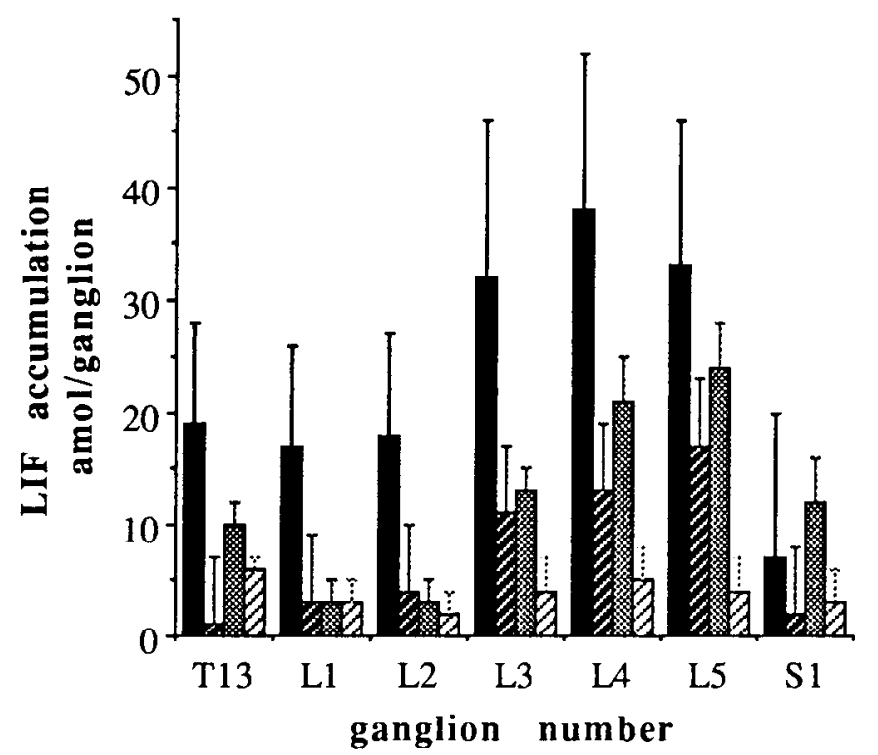

Figure 4. Retrograde transport of ${ }^{125}$ I-LIF into sensory ganglia in newborn mice. ${ }^{125} \mathrm{I}$-LIF was injected into 2-d-old mice, and sensory ganglia were processed and are identified as described in Figure $3 \mathrm{~A}$.

However, in the same animals that received injections into the muscle, there was no detectable radioactivity in the spinal cord in adults (ipsilateral, $3.0 \pm 0.7 \mathrm{cpm}$; contralateral, $2.9 \pm 1.0$ cpm) or neonates (ipsilateral, $9.9 \pm 1.9 \mathrm{cpm}$; contralateral, 6.6 $\pm 0.9 \mathrm{cpm}$ ) indicating that there was no, or at least undetectable, retrograde transport of ${ }^{125}$ I-LIF into spinal motor neurons.

Autoradiographic examination of histological sections of L4 ganglia taken from both adult and newborn animals after injection with ${ }^{125}$ I-LIF into the footpad revealed the presence of radioactive material in a subpopulation of neurons. Figure 5 shows micrographs of sections of ganglia from newborn mice injected with ${ }^{125}$ I-LIF. Grains appeared specifically over the neurons and were never present over non-neuronal cells, which again is consistent with a specific retrograde transport of ${ }^{125} \mathrm{I}$ LIF in the sensory axons. Grain counts of the neuronal sections showed that approximately $10 \%$ of the neurons were labeled significantly over the background level (Fig. 6), indicating that this proportion of the neurons had retrogradely transported ${ }^{125} I-$ LIF. In addition, autoradiographic examination of spinal cord sections from mice injected into the muscle did not reveal any neurons that had more than background numbers of grains (data not shown).

footpad injection and ipsilateral (stippled) and contralateral (lightly hatched) after muscle injection. Numbers are the means and SEM of nine determinations. An amole is approximately $1.1 \mathrm{cpm}$ for ${ }^{125}$ I-LIF. $B$. Elimination of transport of ${ }^{125}$ I-LIF in the presence of excess cold LIF. ${ }^{125}$ I-LIF was injected into the footpad of adult mice either alone or in the presence of a 900-fold excess of unlabeled LIF, and DRG were analyzed as in $A$. Shown are accumulation into ipsilateral ganglia of LIF alone (black) or in the presence of cold LIF (heavily hatched), or into contralateral ganglia of LIF alone (stippled) or in the presence of cold LIF (lightly hatched). Numbers are means and SEM of six determinations. $C$, Failure of specific accumulation of ${ }^{125} \mathrm{I}-\mathrm{FGF}$ in sensory ganglia of adult mice after injection into footpad or gastrocnemius muscle. Shown are accumulation of ${ }^{125}$ I-FGF into ganglia as described in $A$. Numbers are means and SEM of eight determinations. For ${ }^{125} \mathrm{I}-\mathrm{FGF}$, an amole is approximately $1.7 \mathrm{cpm}$. 
Figure 5. Autoradiographic analysis of sections of DRG containing retrogradely transported ${ }^{125}$ I-LIF. Ganglia (L3-L5) from newborn mice, treated as described in Figure 3, were embedded in paraffin, sectioned, mounted, autoradiographed, and counterstained. Shown are sections through L4 ganglia at low $(A)$ and high $(B)$ power. Scale bar: $A, 50 \mu \mathrm{m} ; B, 20 \mu \mathrm{m}$.
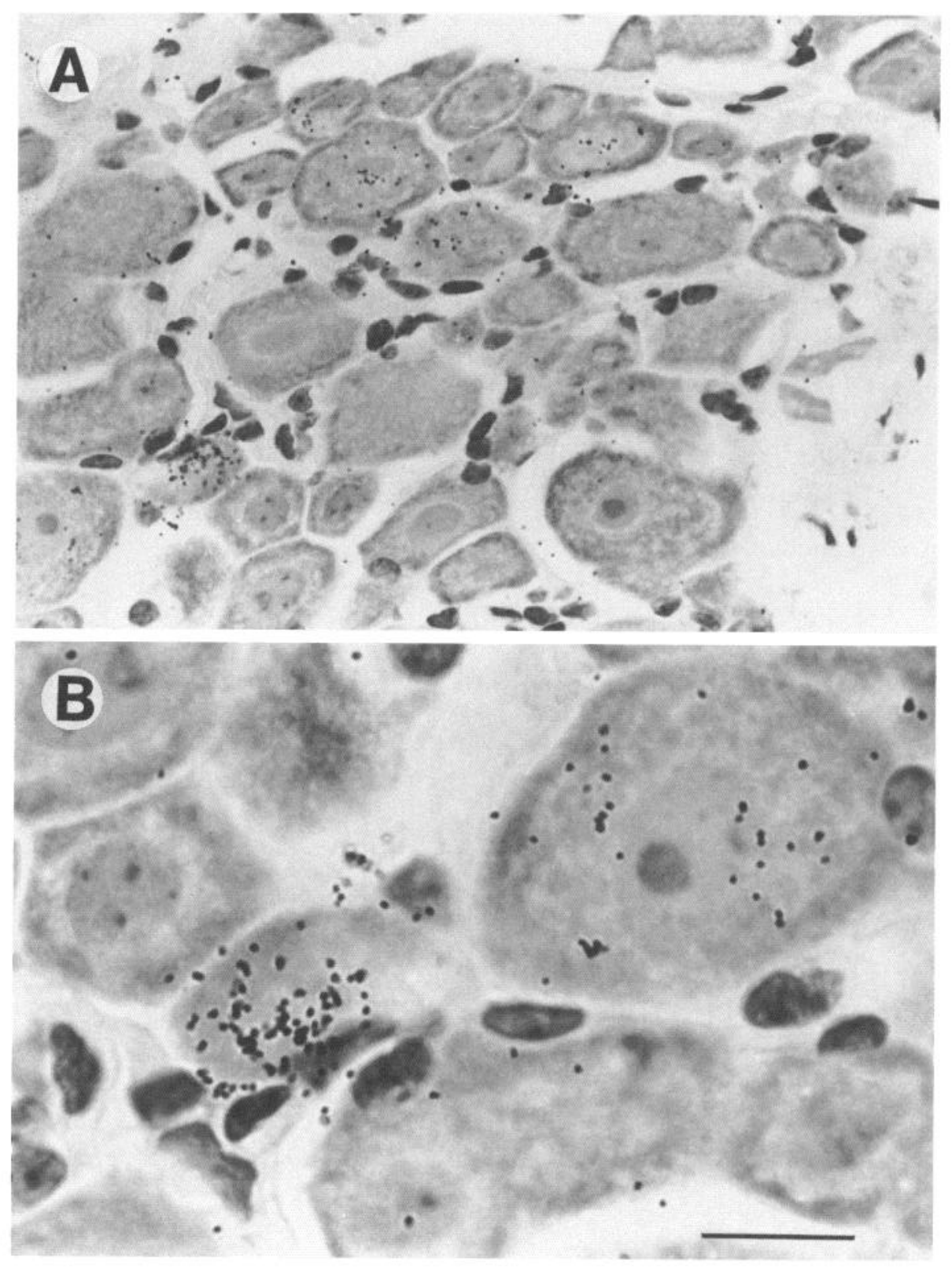

No evidence of transport of LIF into sympathetic ganglia

In view of its suggested role as a cholinergic differentiation factor (Yamamori et al., 1989), we investigated whether LIF could be transported into the sympathetic ganglia from the footpad or from other regions of sympathetic innervation. To investigate this possibility, the footpad was again injected with ${ }^{125} \mathrm{I}-\mathrm{LIF}$ and after 16-24 hr the lumbar ganglia of the sympathetic chain were removed and radioactivity determined. As shown in Table 2, only background counts were found in the lumbar ganglia on either the ipsilateral or the contralateral side. In addition, injection of ${ }^{125}$ I-LIF into the front paw or the anterior chamber of the eye, followed by determination of counts accumulated in the superior cervical ganglion or the stellate ganglion, showed no evidence of transport of LIF into either of these sympathetic ganglia (Table 2).

\section{Discussion}

It has been shown in this study that mature sensory neurons bind significant quantities of ${ }^{125} \mathrm{I}$-LIF, and that this binding is eliminated by the addition of an excess of cold LIF, indicating that these neurons have specific receptors for LIF. The concentration of the radiolabeled ligand used in these experiments and the elimination of binding with cold LIF suggest that the receptors on the neurons are high affinity and are probably of the same type as those found on other cell types such as those of the monocyte/macrophage lineage (Hilton et al., 1988, 1991). We have not undertaken a Scatchard analysis of receptor binding to these cells in order to determine the dissociation constants for receptor binding because it was impractical to obtain enough cells for this analysis; however, the observation that both cells in the monocyte/macrophage lineage and sensory neurons respond to LIF over the same concentration range (Murphy et al., 


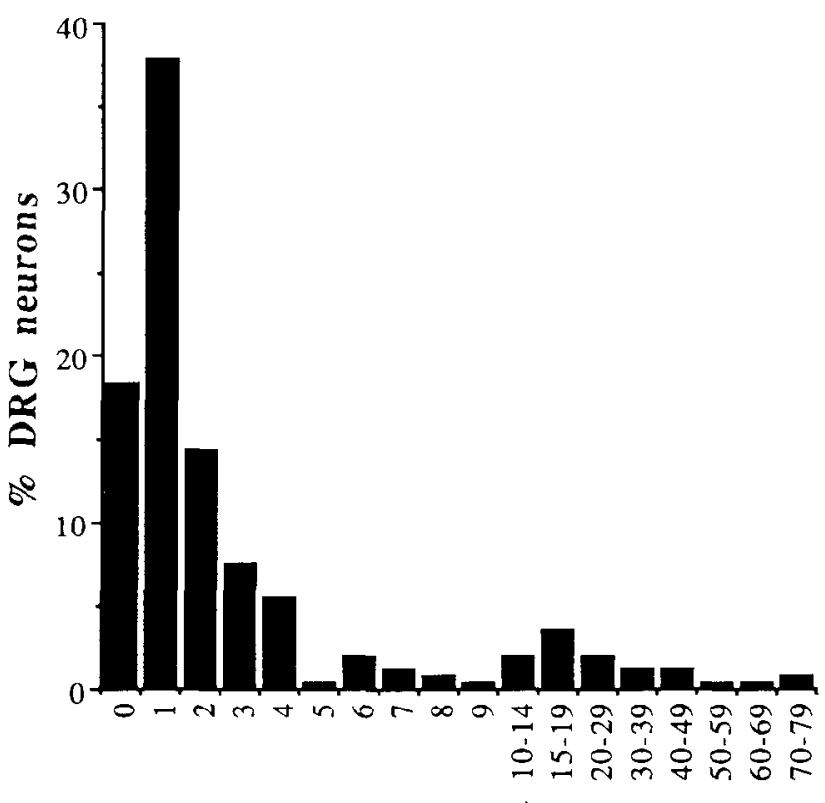

grains/cell

Figure 6. Distribution of grain counts in sensory neurons containing retrogradely transported ${ }^{125}$ I-LIF. Numbers are the grain counts in one section for each cell in L4 ganglia obtained as described in Figure 5.

1991 ) is consistent with the idea that the receptors in both cell types are the same high-affinity receptors.

The other cells in these cultures did not bind appreciable quantities of ${ }^{125}$ I-LIF, showing that only the sensory neurons are capable of responding to LIF. This supports the concept that the action of LIF in supporting neuronal survival in vitro is a consequence of direct binding to neurons, as was postulated as a result of previous limiting dilution studies in which LIF supported the survival of very low numbers of sensory neurons (Murphy et al., 1991).

Previous studies with radiolabeled NGF have shown that both Schwann cells and neurons bind NGF in vitro, although it is not clear whether this is due to upregulation of NGF receptors in vitro. In this way, LIF is different from NGF, being specific for neuronal cells in the DRG and in addition having a range of other activities outside the nervous system, at least in in vitro culture systems. While it has been argued that receptor upregulation in vitro may account for the widespread expression of receptors, such as NGF, it is most unlikely that aberrant receptor expression could account for the restricted distribution of re- ceptors found in this experiment. The expression of receptors on the majority of sensory neurons is in agreement with previous results showing the majority of sensory neurons survive in vitro in the presence of LIF (Murphy et al., 1991).

The receptor for LIF has recently been cloned from a human placental cDNA library and been shown to be a member of an expanding family of cytokine and hemopoietin receptors characterized by a structurally conserved extracellular domain (Gearing et al., 1991). Interestingly, the receptor for CNTF has also been shown to belong to this receptor family although it contains no transmembrane region and is instead anchored in the membrane by a glycosyl-phosphatidyl inositol linkage (Davis et al., 1991). Superficially, receptors for the NGF-related neurotrophic factors are unrelated to the receptors for LIF or CNTF but the recently demonstrated involvement of second signal-transducing subunits (trk proteins) in the receptor complexes (Hempstead et al., 1991; Kaplan et al., 1991) suggests that the signaling mechanism of NGF receptors may have some broad similarities to those described for members of the cytokine receptor family such as interleukins 2 and 6 and granulocyte-macrophage colony stimulating factor (see Davis et al., 1991).

The major finding of this report is that LIF is retrogradely transported. This reinforces the view that the expression of LIF receptors by sensory neurons is not an in vitro artifact and, more importantly, further implicates LIF's role as a neurotrophic molecule for sensory neurons. FGF does not appear to be retrogradely transported in the sciatic nerve (see also Ferguson et al., 1990; Hendry and Belford, 1991), although there is evidence that FGF can be transported anterogradely in retinal ganglion cells (Ferguson et al., 1990). LIF is not transported by motor neurons in the sciatic nerve, nor is there any evidence from this study that it is transported into sympathetic ganglia, which is surprising given the effect of LIF on sympathetic neurons (Yamamori et al., 1991). However, the experiments reported in this study do not exclude the possibility that a small subpopulation of the sympathetic neurons in the ganglia investigated do transport LIF.

The similarities of action of NGF and LIF on sensory neurons suggest that the process of retrograde transport may be necessary to deliver a sufficient biological signal from the periphery to the cell soma. However, as cytoplasmically injected NGF is not biologically active and intracellular anti-NGF antibodies do not block its action (Heumann et al., 1981), it suggests that it is the receptor-ligand complex that is important in signal delivery. The requirement for the retrograde transport of the receptorligand complex may reflect an instability of the second message.

Table 2. Lack of observable transport of LIF into sympathetic ganglia

\begin{tabular}{llcl} 
& & \multicolumn{2}{l}{$\begin{array}{l}\text { Accumulation of }{ }^{125} \text { I-LIF } \\
\text { (amol/ganglion) }\end{array}$} \\
\cline { 3 - 4 } Injection site & Ganglion measured & Ipsilateral & Contralateral \\
\hline Footpad & Lumbar & $3.2 \pm 1.6$ & $4.5 \pm 1.1$ \\
Front paw & Superior cervical & $5.3 \pm 2.2$ & $1.7 \pm 1.4$ \\
Eye (anterior chamber) & Stellate & $1.6 \pm 0.6$ & $0.8 \pm 0.6$ \\
& Superior cervical & $11.2 \pm 4.1$ & $7.2 \pm 1.5$
\end{tabular}

125I-LIF $(0.5 \mu \mathrm{Ci})$ was injected into the footpad, front paw, or eye of adult mice, and the particular ganglia were removed 16-24 hr later and radioactivity determined. Numbers are as in Table 1 . Since there is no direct sympathetic innervation of the front paw from the superior cervical ganglion, the counts found in this ganglion following injection of the front paw act as a background control. 
Alternatively, the main function of the factor could be to cluster receptors on endocytotic vesicles, resulting in the retrograde transport of the receptors and perhaps their associated tyrosine kinase activities, which might subsequently phosphorylate particular substrates on arrival at the cell body. It is also possible that the transport of the factor serves primarily to carry it to the lysosomes. Also transported are the downstream changes evoked by the factor (phosphorylated protein or other), and it is these that are functionally important. In these cases, the iodinated ligand would be acting as a specific tracer, temporally but not functionally associated with these events.

The precise role of LIF in the development and maintenance of the sensory nervous system has yet to be determined and in particular when and where it may behave as a neurotrophic factor in vivo. NGF has been shown to be required in vivo by the use of antibodies transferred via the placenta to the embryo from mothers immunized with NGF (see Johnson et al., 1986). LIF may act at different times to NGF, or alternatively there may be interactions within the nervous system involving both LIF and the other neurotrophins that result in the control of the development of the sensory nervous system. In addition, there may be spatial- and temporal-specific expression patterns for LIF and the NTs that determine their activities on subsets of sensory neurons in vivo.

\section{References}

Barbin G, Manthorpe M, Varon S (1984) Purification of chick eye ciliary neuronotrophic factor. J Neurochem 43:1468-1478.

Bartlett PF, Murphy M (1991) Nerve growth factors. Today's Life Sci 3:12-20.

Bartlett PF, Murphy M (1992) Epigenetic regulation of the early development of the nervous system. Adv Cell Mol Biol, in press.

Calvo JC, Radicella JP, Charreau EH (1983) Measurement of specific radioactivities in labelled hormones by self-displacement analysis. Biochem J 212:259-264.

Contreras MA, Bale NF, Spar IL (1983) Iodine monochloride (ICI) iodination techniques. Methods Enzymol 92:277-292.

Cowan WM (1970) Anterograde and retrograde transneuronal degeneration in the central and peripheral nervous system. In: Contemporary research methods in neuroanatomy (Nauta WJH, Ebesson SOE, eds), pp 217-251. New York: Springer.

Davis S, Aldrich TH, Valenzuela DM, Wong V, Furth ME, Squinto SP, Yancopoulos GD (1991) The receptor for ciliary neurotrophic factor. Science 253:59-63.

Drago J, Murphy M, Carroll SM, Harvey RP, Bartlett PF (1991) Fibroblast growth factor-mediated proliferation of central nervous system precursors depends on endogenous production of insulin-like growth factor 1. Proc Natl Acad Sci USA 88:2199-2203.

Ferguson IA, Schweitzer JB, Johnson EM (1990) Basic fibroblast growth factor: receptor-mediated internalization, metabolism, and anterograde axonal transport in retinal ganglion cells. J Neurosci 10:21762189.

Gearing DP, Gough NM, King JA, Hilton DJ, Nicola NA, Simpson RJ, Nice EC, Kelso A, Metcalf D (1987) Molecular cloning and expression of cDNA encoding a murine myeloid leukemia inhibitory factor (LIF). EMBO J 6:3995-4002.

Gearing DP, Thut CJ, Vanden Bos T, Gimpel SV, Delaney PB, King J, Price V, Cosman D, Beckmann MP (1991) Leukemia inhibitory factor receptor is structurally related to the IL-6 signal transducer gp 130. EMBO J 10:2839-2848.

Hamburger V (1934) The effects of wing bud extirpation on the development of the central nervous system in chick embryos. J Exp Zool 68:449-494.

Hamburger V (1975) Cell death in the development of the lateral motor column of the chick embryo. J Comp Neurol 160:535-546.

Hamburger V (1977) The developmental history of the motor neuron. The F. O. Schmitt lecture in neuroscience. Neurosci Res Program Bull 15:1-37.

Hempstead BL, Martin-Zanca D, Kaplan DR, Parada LF, Chao MV (1991) High-affinity NGF binding requires coexpression of the $t r k$ proto-oncogene and the low-affinity NGF receptor. Nature 350:678683.

Hendry IA (1976) Control of the development of the vertebrate sympathetic nervous system. In: Reviews of neuroscience (Ehrenpris S, Kopin IJ, eds), pp 149-194. New York: Raven.

Hendry IA, Belford DA (1991) Lack of retrograde axonal transport of the heparin binding growth factors by chick ciliary neurons. Int $\mathrm{J}$ Dev Neurosci 9:243-250.

Heumann R, Schwab M, Thoenen H (1981) A second messenger required for nerve growth factor biological activity? Nature 292:838840.

Hilton DJ, Nicola NA, Metcalf D (1988) Specific binding of murine leukemia inhibitory factor to normal and leukemic monocytic cells. Proc Natl Acad Sci USA 85:5971-5975.

Hilton DJ, Nicola NA, Metcalf D (1991) Distribution and comparison of receptors for leukemia inhibitory factor on murine hemopoietic and hepatic cells. J Cell Physiol 146:207-215.

Hohn A, Leibrock J, Bailey K, Barde Y-A (1990) Identification and characterization of a novel member of the nerve growth factor/brain derived neurotrophic factor family. Nature 344:339-341.

Johnson EM, Rich KM, Yip HK (1986) The role of NGF in sensory neurons in vivo. Trends Neurosci 9:33-37.

Kaplan DR, Martin-Zanca D, Parada LF (1991) Tyrosine phosphorylation and tyrosine kinase activity of the $t r k$ proto-oncogene product induced by NGF. Nalure 350:158-160.

Leibrock J, Lottspeich F, Hohn A, Hofer M, Hengerer B, Masiakowski P, Thoenen H, Barde Y-A (1989) Molecular cloning and expression of brain-derived neurotrophic factor. Nature 341:149-152.

Levi-Montalcini R, Angelletti PU (1968) Nerve growth factor. Physiol Rev 48:534-569.

Murphy M, Drago J, Bartlett PF (1990) Fibroblast growth factor stimulates the proliferation and differentiation of neural precursor cells in vitro. J Neurosci Res 25:463-475.

Murphy M, Reid K, Hilton DJ, Bartlett PF (1991) Generation of sensory neurons is stimulated by leukemia inhibitory factor. Proc Natl Acad Sci USA 88:3498-3501.

Oppenheim RW (1989) The neurotrophic theory and naturally occurring motoneuron death. Trends Neurosci 12:252-255.

Otto D, Unsicker K, Grothe C (1987) Pharmacological effects of nerve growth factor and fibroblast growth factor applied to the transectioned sciatic nerve on neuron death in adult rat dorsal root ganglia. Neurosci Lett 83:156-160.

Purves D, Snyder WD, Voyvodic JT (1988) Trophic regulation of nerve cell morphology and innervation in the autonomic nervous system. Nature 336:123-128.

Stöckli KA, Lottspeich F, Sendtner M, Masiakowski P, Carroll P, Goetz $R$, I indholm D, Thoenen H (1989) Molecular cloning, expression and distribution of ciliary neurotrophic factor. Nature 342:920-923.

Thoenen H, Edgar D (1985) Neurotrophic factors. Science 229:238242.

Yamamori T, Fukada K, Aebersold R, Korsching S, Fann MJ, Patterson PH (1989) The cholinergic neuronal differentiation factor from the heart cells is identical to leukemia inhibitory factor. Science 246: $1412-1416$. 